Article

\title{
General Technical Approvals for Decentralised Sustainable Urban Drainage Systems (SUDS) - The Current Situation in Germany
}

\section{Carsten Dierkes ${ }^{1, \dagger}$, Terry Lucke ${ }^{2, \dagger, *}$ and Brigitte Helmreich ${ }^{3, \dagger}$}

1 Urban Water Management, Frankfurt University of Applied Sciences, D-60318 Frankfurt, Germany; E-Mail: Carsten.Dierkes@fb1.fh-frankfurt.de

2 Stormwater Research Group, University of the Sunshine Coast, Sippy Downs QLD 4556, Australia

3 Urban Water Systems Engineering, Technical University of Munich, D-80333 Munich, Germany; E-Mail: b.helmreich@tum.de

$\dagger$ These authors contributed equally to this work.

* Author to whom correspondence should be addressed; E-Mail: tlucke@usc.edu.au; Tel./Fax: +61-7-5456-5185.

Academic Editor: Marc A. Rosen

Received: 20 December 2014 / Accepted: 5 March 2015 / Published: 13 March 2015

\begin{abstract}
The use of decentralised, sustainable urban drainage systems (SUDS) for the treatment of stormwater runoff is becoming increasingly prevalent in Germany. Decentralised SUDS can offer a viable and attractive alternative to end of pipe treatment systems for stormwater runoff from urban areas. However, there is still some uncertainty regarding the long-term performance of SUDS, and the general legislative requirements for SUDS approval and testing. Whilst the allowable pollution levels in stormwater runoff that infiltrate into ground and/or water table are regulated across Germany by the Federal Soil Protection Law, there is presently no federal law addressing the discharge requirements for surface water runoff. The lack of clear guidance can make it difficult for planners and designers to implement these innovative and sustainable stormwater treatment systems. This study clarifies the current understanding of urban stormwater treatment requirements and new technical approval guidelines for decentralised SUDS devices in Germany. The study findings should assist researchers, designers and asset managers to better anticipate and understand the performance, effective life-spans, and the planning and maintenance
\end{abstract}


requirements for decentralised SUDS systems. This should help promote even greater use of these systems in the future.

Keywords: sustainable urban design; stormwater pollution; water sensitive urban design; proprietary systems

\section{Introduction}

The use of decentralised, sustainable urban drainage systems (SUDS) for the treatment of stormwater runoff is becoming increasingly prevalent in Germany. However, there is still some uncertainty regarding the long-term performance of SUDS, and the general legislative requirements for SUDS approval and testing. This paper provides a practical outline of the current urban stormwater treatment requirements, and of the general technical approval processes for decentralised SUDS devices in Germany.

Decentralised SUDS systems are generally used for treatment of stormwater runoff at source before it reaches downstream receiving waters, or before groundwater infiltration occurs. SUDS are particularly suitable in dense urban environments as they can provide viable alternatives to more common centralised treatment solutions such as large end-of-line sedimentation tanks and retention-type soil filters. Decentralised SUDS can be more attractive options than centralised systems from both water conservation and economic perspectives. Figure $1 \mathrm{a}-\mathrm{f}$ shows a variety of typical SUDS devices used in Australia, Germany, and the United States.

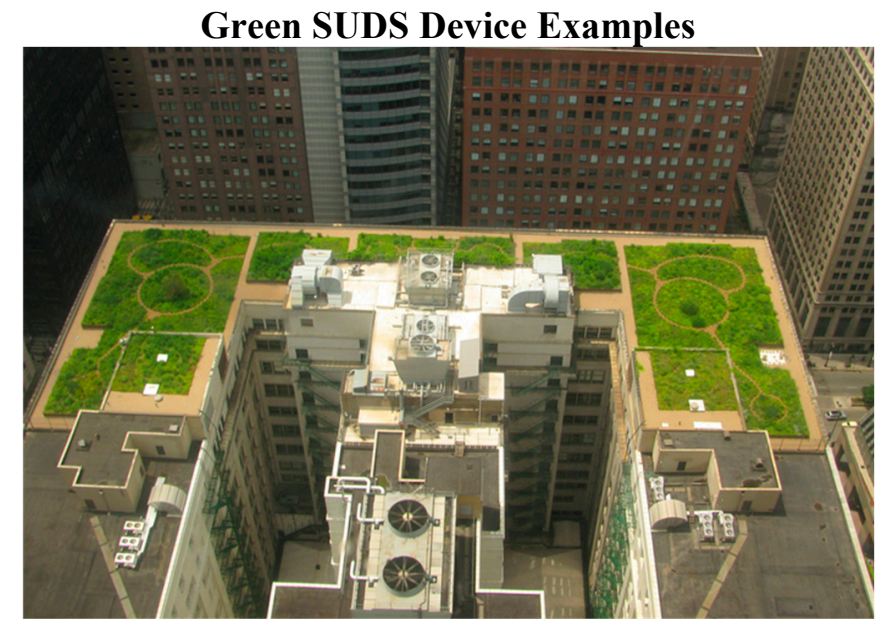

(a) Green Roof [1]
Technical SUDS Device Examples

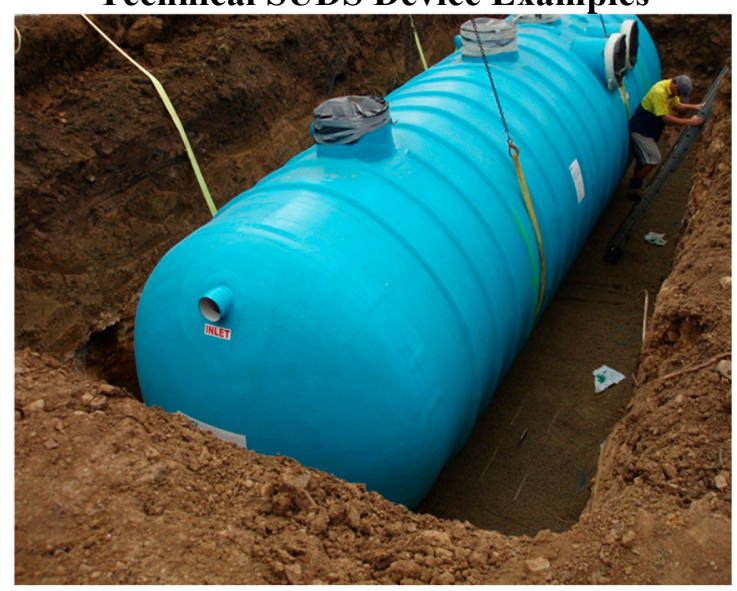

(d) Sedimentation Tanks [2]

Figure 1. Cont. 


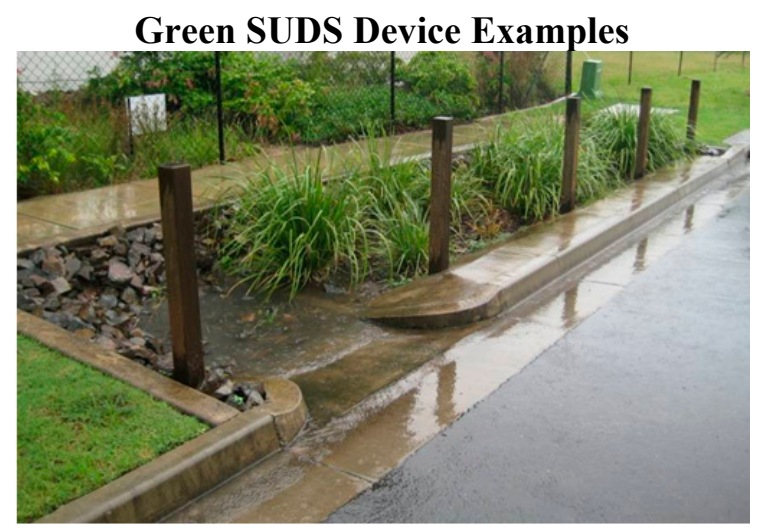

(b) Bioretention System

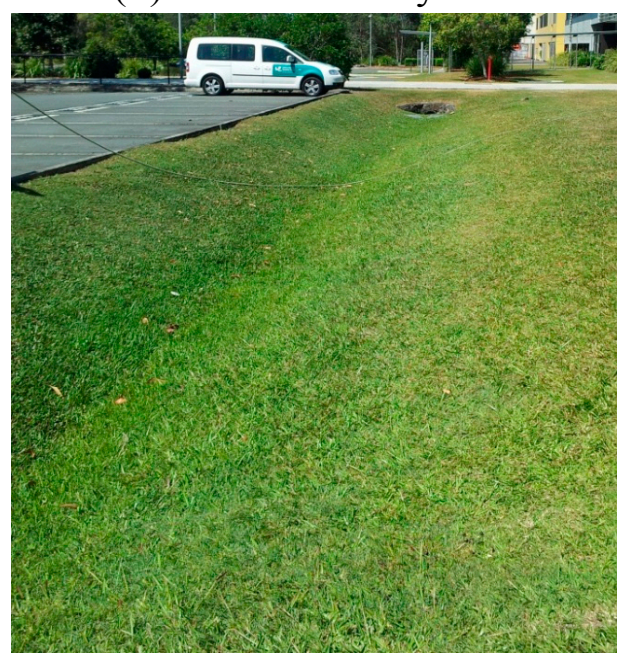

(c) Grassed Swale

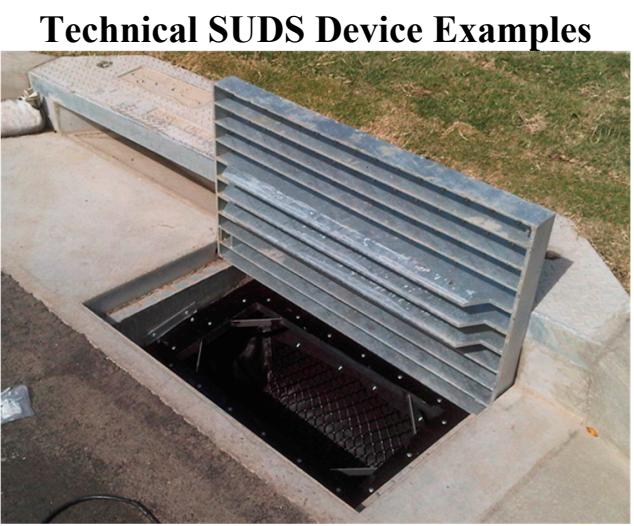

(e) Silt Baskets [3]

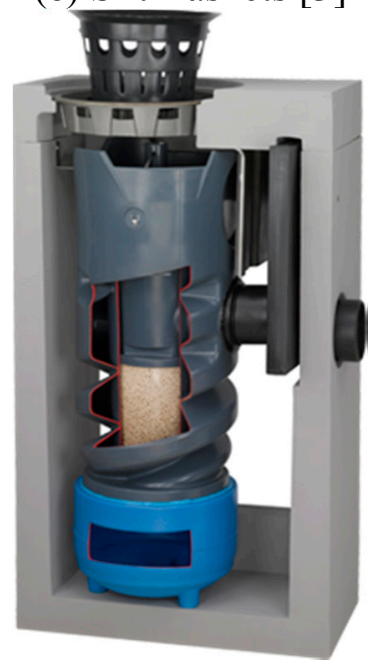

(f) Filter Gully [4]

Figure 1. (a-f) Typical Green and Technical sustainable urban drainage systems (SUDS) devices.

There is a variety of different decentralised SUDS devices available with different functions. Some of these, such as swales, bioretention systems, and green roofs are generally classified as "Green" SUDS (Figure 1a-c) as their treatment processes are primarily performed through naturally occurring filtration and biological processes. In Europe, green SUDS are classified as industry best management practice (BMP) devices and can generally be constructed without specific approval from stormwater management authorities [5]. The soil media and vegetation contained in these systems are responsible for the majority of the stormwater pollutant removal processes. Typical pollutants contained in stormwater runoff include: total suspended solids (TSS); nutrients described as total phosphorus (TP) and total nitrogen $(\mathrm{TN})$; heavy metals including copper $(\mathrm{Cu})$ and zinc $(\mathrm{Zn})$; and organics such as polycyclic aromatic hydrocarbons (PAH) and other hydrocarbons (HC) [6]. The pollution removal efficiency of green SUDS generally varies with the composition of the media used and the different vegetation types. The range of this removal is often reported as between approximately $50 \%$ and $90 \%, 30 \%$ and $60 \%$, and $10 \%$ and $40 \%$ for TSS, TP and TN respectively, and is therefore considered relatively high [6].

Other SUDS, including sedimentation and filtration devices, are classified as "Technical" systems (Figure $1 \mathrm{~d}-\mathrm{f}$ ) as their treatment processes are based on physical adsorption, precipitation, and chemical processes. Technical SUDS, or also known as proprietary devices, often target different stormwater pollutants and operate using different treatment processes than Green SUDS and their pollution 
removal efficiencies can be quite different. Testing is therefore generally performed to evaluate their removal rates for different pollutants. Field testing results are often highly variable due to different site conditions and other environmental influences; therefore a standard laboratory testing procedure [7] is generally conducted. Although there can be many different pollutants entrained in stormwater runoff, most SUDS testing procedures only test for the removal of the most common pollutants. This ensures that the testing procedures remain relatively straight forward and simple to perform.

One of the major differences between Green and Technical SUDS is the hydraulic and pollutant load per area (volume) and time. Some researchers have suggested that the difference could be better described as low and high rate treatment systems. However, this paper considers both types of systems in the analysis.

Previously in Germany, stormwater runoff from a variety of different catchments was often collected and mixed together in underground stormwater pipes and then transported to a centralised facility for treatment (Figure 2). The quality of the stormwater runoff from the different catchments could be highly variable ranging from relatively clean runoff from grassed areas and residential house roofs to heavily polluted runoff from large industrial estates [5,8-10]. This "cocktail" of stormwater runoff was then usually all treated together as one wastewater product at the centralised treatment facility (Figure 1). This was generally a relatively inefficient and expensive way of processing stormwater runoff. New federal regulations have been introduced in Germany [11] which stipulate that in future, heavily polluted stormwater runoff should be treated separately at source, instead of mixing it in with relatively clean stormwaters and sending it all to a central treatment facility as was done in the past (Figure 2). These regulations are also being applied as State Water Laws in some German States. For example, a state regulation from North Rhine Westphalia [12] is being used as one of the main technical references for development of new federal regulations for stormwater treatment in Germany (DWA A-102).

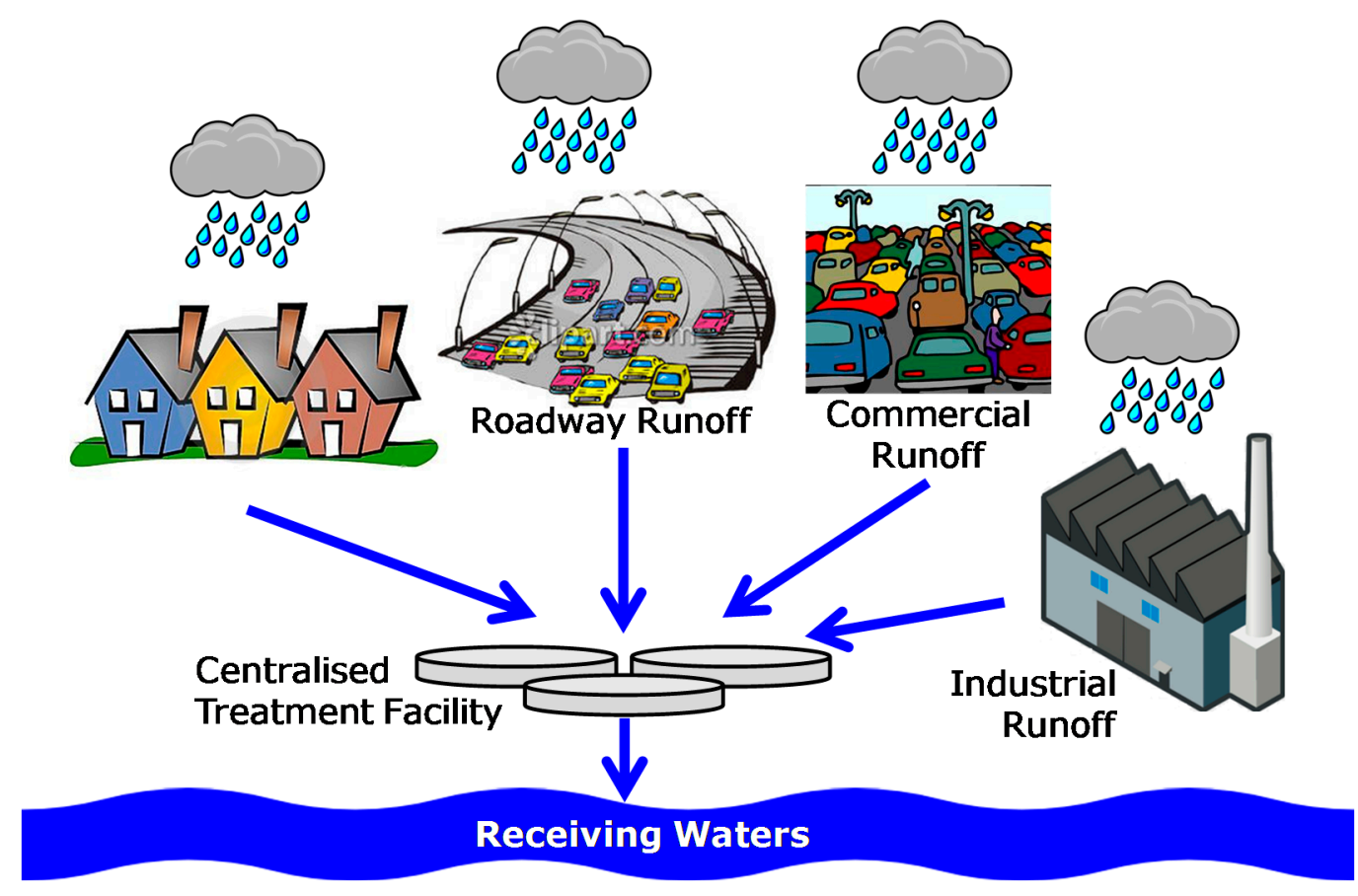

Figure 2. Schematic of typical centralised water treatment facility. 
One of the main advantages of adopting a decentralised SUDS approach is that SUDS devices can be designed and adapted to target and remove specific stormwater pollutants at source. For example, the pollutants removed from heavily pollutant stormwater runoff from industrial estates can be collected and stored in the sludge chambers and filters of Technical SUDS devices for later removal as part of the general maintenance procedures. This ensures that potentially harmful pollutants are not widely dispersed across the catchment area.

This decentralised SUDS approach means that relatively clean stormwater runoff, which typically represents the largest portion of catchment runoff can be discharged directly to receiving waters, generally with limited treatment (Figure 3). This means that appropriate levels of stormwater treatment can be applied at the correct locations (Figure 3), and the associated treatment costs can then be met by those directly responsible for the pollution, instead of being passed on to the community.

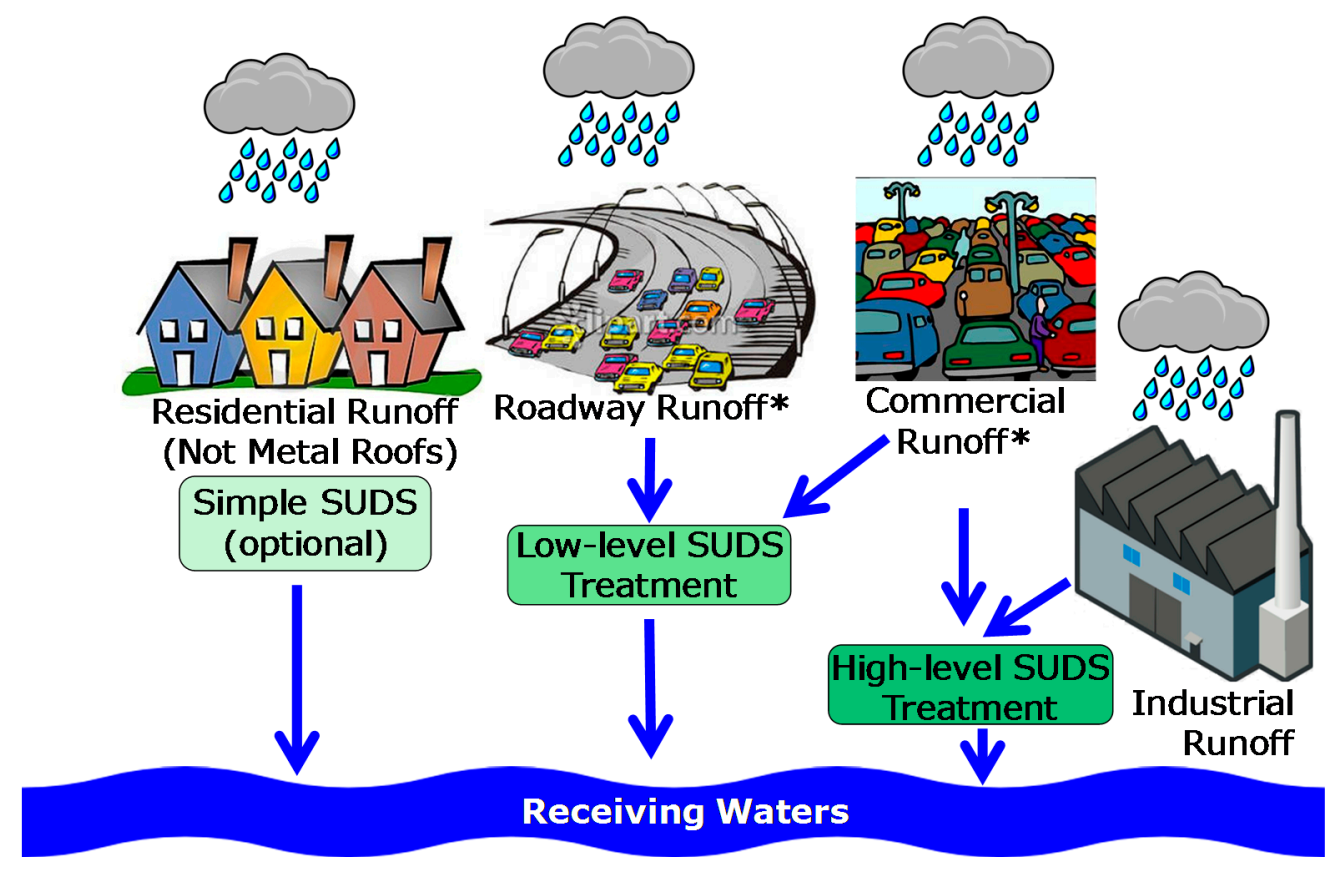

Figure 3. Schematic of typical decentralised SUDS water treatment options (* Highly contaminated roadway runoff often requires higher-lever SUDS treatment).

Although treating stormwater with decentralised SUDS has many advantages over using traditional centralised treatment facilities, it is not always the best option in every case, as it depends on the specific environmental and infrastructure conditions within each catchment. For example, if an appropriately sized and functional stormwater drainage system and centralised treatment facility already exists in an urban catchment then continuing with this approach may still be the best alternative. The individual maintenance requirements of the different systems is another important issue that needs to be considered in the decision making process. While on-going maintenance of centralised stormwater treatment facilities can be relatively straight-forward and routine, ensuring SUDS devices are appropriately maintained can often pose significant challenges. This can be particularly complicated in situations where the ownership of SUDS assets may be transferred from the developer or land owner, to the local council after a certain time period has expired as part of the development conditions. Long-term maintenance contracts for decentralised SUDS may be required 
and while specialised maintenance companies can be contracted to undertake SUDS systems, this will result in on-going maintenance costs, and this also needs to be considered when making decisions for or against the implementation of SUDS devices over decentralised treatment facilities.

The main differences between centralised and decentralised stormwater treatment systems are the characteristics and levels of pollution contained in the stormwater runoff. For example, while TSS loads can be in the range of $400 \mathrm{~kg} / \mathrm{ha} / \mathrm{year}$ ) for the influent of centralised treatment systems, TSS loads can be up to ten times greater than that value in stormwater runoff generated from the small catchment areas that are typically treated by decentralised SUDS devices. The main reason for these increased TSS loads is that only surfaces producing substantial pollution loads are connected to the decentralised systems, while the typical stormwater runoff treated by centralised facilities is a mixture of both clean and polluted stormwater. In addition, decentralised SUDS devices are often exposed to higher pollution loads originating from local construction activities, tree litter or pollen and even seasonal agricultural activities. This paper focuses on the pollution of surface waters receiving urban stormwater runoff.

\section{Classification of Stormwater Types}

Stormwater runoff in Germany is broadly categorised into two different types: (1) Stormwater runoff that is infiltrated into the soil and water table (Groundwater Runoff); and (2) Stormwater runoff that is discharged into streams and receiving waters (Surface Water Runoff).

In Germany, Groundwater Runoff (GR) is regulated by the Federal Soil Protection Law [13]. Developments discharging GR are required to comply with this law, which recommends permissible limits and maximum loads for various pollutants for water infiltrating into groundwater aquifers. This law enables local government authorities (LGAs) to enforce the implementation of stormwater quality improvement measures on developments within their local catchments.

At present, there is no federal law in Germany addressing the discharge requirements for Surface Water Runoff (SWR) and the anticipated requirements for developments discharging to SWR are still unclear. However, the Federal Ministry for the Environment (BMU) and the Federal Environmental Agency (UBA) have both requested the development of new federal guidelines for stormwater treatment. National guidelines for permissible pollutant limits for the discharge of SWR are currently under discussion. While LGAs can still enforce generic stormwater treatment measures for developments generating SWR, the specific treatment requirements, or the permissible limits for different stormwater pollutants, are generally not stipulated. On the other hand some German states, such as North Rhine Westphalia (NRW), enforce their own strict regulations [14] relating to the discharge of SWR. These regulations can include very detailed requirements on the classification of different stormwater runoff types and on the required treatment measures and allowable discharge water quality (Figure 4). These are described in more detail below. 
No Treatment

(No Metal Roofs)

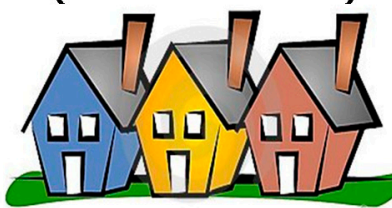

Category 1

Clean Runoff $<300$ Vehicles/day

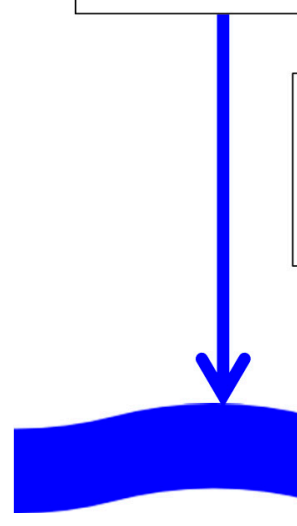

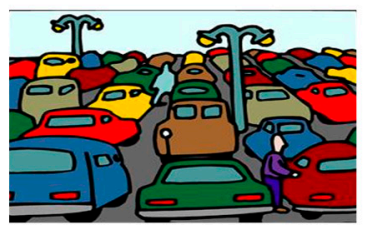

Category 2 Low Pollution Runoff $<15,000$ Vehicles/day

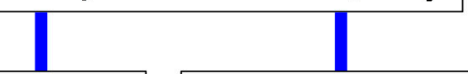

Sediment Traps, Hydrodynamic

Separators, Lamellae Clarifiers

\section{(NRW) [12] and typical SUDS treatments.}

Figure 4. Three categories of surface water runoff (SWR) in North Rhine Westphalia

North Rhine Westphalia has adopted its own classification system for SWR [12] which stipulates different levels of stormwater treatment depending of the land use of the catchment area discharging the runoff. Three different stormwater runoff categories are specified and these are generally related to either the number of vehicles passing through the area each day (Figure 4), or to the type of roofing materials used on the buildings. All SWR discharging from developments must be classified into one of the three categories. The three SWR categories are explained in Table 1.

Table 1. North Rhine Westphalia surface water runoff (SWR) categories.

\begin{tabular}{|c|c|c|}
\hline \multicolumn{3}{|c|}{ Surface Water Runoff (SWR) Category } \\
\hline Category 1 & Category 2 & Category 3 \\
\hline $\begin{array}{l}\text { Category } 1 \text { SWR } \\
\text { contains clean } \\
\text { runoff from } \\
\text { non-metal roofs and } \\
\text { areas with no or } \\
\text { low traffic density } \\
\text { (less than } 300 \\
\text { vehicles/day). }\end{array}$ & $\begin{array}{l}\text { Category } 2 \text { SWR must be treated before it is discharged } \\
\text { into receiving waters or infiltrated into the ground. The } \\
\text { following types of surface are classified as Category } 2 \\
\text { (lightly polluted) runoff: } \\
\text { - } \quad \text { roof areas in commercial or industrial zones (not } \\
\text { metal roofs); } \\
\text { - parking lots (except those mentioned in category 3); } \\
\text { - paved areas with low traffic density (flowing and } \\
\text { stationary >300 vehicles/day), such as residential } \\
\text { streets and parking lots; } \\
\text { - distributors and road connections; }\end{array}$ & $\begin{array}{l}\text { The following types of surface are } \\
\text { classified as Category } 3 \text { (heavy } \\
\text { polluted) runoff: } \\
\text { - areas with high traffic density e.g., } \\
\text { arterial roads, motorways, } \\
\text { highways, car parks with high } \\
\text { traffic density (roads with more } \\
\text { than } 15,000 \text { vehicles/day); } \\
\text { roof water runoff from all } \\
\text { buildings with metal roofs; and }\end{array}$ \\
\hline
\end{tabular}


Table 1. Cont.

\begin{tabular}{|c|c|c|}
\hline \multicolumn{3}{|c|}{ Surface Water Runoff (SWR) Category } \\
\hline Category 1 & Category 2 & Category 3 \\
\hline & $\begin{array}{l}\text { - } \text { shopping streets, market places, areas where outdoor } \\
\text { events take place; } \\
\text { - commercial and industrial areas with low traffic } \\
\text { density and no handling of hazardous substances; } \\
\text { - } \text { agricultural areas, if not included in Category 3; and } \\
\text { - runways and taxiways at airports without winter } \\
\text { operation (de-icing). }\end{array}$ & $\begin{array}{l}\text { yards and other areas in } \\
\text { commercial zones that are not } \\
\text { mentioned in Category } 2 \text {. }\end{array}$ \\
\hline
\end{tabular}

The North Rhine Westphalia guidelines [12] recommend that Category 3 SWR from industrial estates be directed towards the next wastewater treatment plant as this stormwater runoff may contain unknown and potentially toxic pollutants, for which the treatment performance by SUDS devices may have not been tested.

The decision on whether to implement decentralised or centralised stormwater treatments systems is also based on economic considerations. In a research project funded by the State of North Rhine Westphalia [13] the performance and life cycle costs of centralised and decentralised facilities were compared. It is important to consider these life cycle costs, because many decentralised facilities can have significant benefits at the installation stage, which are overshadowed by the maintenance costs. The study concluded that the water quality benefits of both centralised and decentralised facilities are comparable. The cost-benefits were found to be variable and highly dependent on the situation in each catchment. For example, the likelihood of a small system failing is larger than a centralised system and the risks associated with each of the systems failing, and the consequences of that need to be considered. Therefore, in order to identify the best solution, the study recommended that each catchment is investigated independently (or on a case by case basis) [13].

\section{Testing Requirements for Decentralised SUDS Devices}

A German Wastewater Association (DWA) working group is currently developing a new federal stormwater treatment guideline titled: "Requirements for stormwater treatment—DWA A102" [15]. In the new DWA A102 guideline, the most common stormwater pollutant, TSS, is classified as an "authoritative evaluation" parameter ("Leitparameter" in German). This means that TSS concentrations can be used as an indicator for potential concentrations of other particulate-based pollutants such as heavy metals and total petroleum hydrocarbons (TPH), which are known to bind to fine sediment particles [7]. This is particularly important for runoff from metal roofs made from copper and zinc as these metals are known to attach to sediment particles smaller than $63 \mu \mathrm{m}$ [7]. However, this is usually of less import for runoff from non-metal roofs and other low-trafficked areas (Category 1 in Figure 4).

First considerations of the new DWA A102 guideline classify sediment into two main sizes: TSS particles less than $63 \mu \mathrm{m}$ in diameter (PM63); and sediment particles greater than $63 \mu \mathrm{m}$. The new guidelines will generally allow Category 1 runoff to be discharged into receiving waters without treatment [12]. The general TSS reduction target for SUDS treatment of Category 2 and 3 stormwater 
runoff will be the removal of at least $50 \%$ of particles smaller than $63 \mu \mathrm{m}$ [15] as these small particles contain the highest loads of micro-pollutants.

There is a variety of different stormwater treatment specifications in Germany including those from the DWA or from individual State regulations. The evaluation and assessment parameters specified in these regulations are often quite different which makes it difficult to undertake a direct comparison between them. However, all German regulations generally address concentrations of TSS and a number of different heavy metal pollutant concentrations. Concentrations of total petroleum hydrocarbons (TPH) are also often regulated. Allowable concentration limits for phosphorous found in stormwater runoff is currently under discussion and this is expected to be addressed in future. Although nitrogen is a well-known stormwater pollutant, this is unlikely to be considered any time soon due to the recognised difficulty in removing dissolved nitrogen species from stormwater runoff.

The Federal Soil Protection Law [14] is used in Germany to regulate the allowable pollutant concentrations of stormwater runoff that will infiltrate into the soil and groundwater (GR). Previously testing conducted on the efficiency of decentralised SUDS treatment devices did not always take into consideration all the required parameters $[16,17]$. This drove the Deutsches Institut für Bautechnik (DIBt) to develop a comprehensive testing methodology for testing proprietary devices. The new stormwater treatment system testing protocol developed by the Deutsches Institut für Bautechnik (DIBt) [7] for testing runoff from road surfaces now includes a number of test pollutant parameters including TSS, copper, zinc, de-icing salts and TPH [7].

The general testing procedures of the General Technical Approval of DIBt in Berlin [18] for decentralised SUDS devices are given below. This approval is only relevant for testing stormwater runoff from road surfaces (with traffic volumes greater than 300 vehicles/day) containing hydrocarbons [16] and is only valid for GR type runoff. As mentioned above, regulations for SWR discharges are still in preparation. The DIBt testing procedure [7] for SUDS devices follows the following general principles:

- the SUDS device must treat $100 \%$ of the stormwater runoff, i.e., no bypass is allowed;

- the SUDS treatment device must comply with all parameters outlined in the Federal Soil Protection Law [13]. This law sets the maximum allowable pollutant concentrations for a range of stormwater pollutants discharged through the SUDS device. The allowable maximum concentrations include:
(1). Copper-50 $\mu \mathrm{g} / \mathrm{L}$
(2). Zinc $-500 \mu \mathrm{g} / \mathrm{L}$
(3). Lead $-25 \mu \mathrm{g} / \mathrm{L}$
(4). Cadmium- $5.0 \mu \mathrm{g} / \mathrm{L}$
(5). $\mathrm{TPH}-200 \mu \mathrm{g} / \mathrm{L}$
(6). There are currently no limits for either TP or TN

- the necessary tests of pollutant removal by the SUDS device are performed in an appropriately equipped laboratory. Discharge concentrations of TSS, copper, zinc, and TPH, as well as the re-mobilizations of heavy metals by de-icing salt (sodium chloride) should be tested; and 
- all filter materials used in the SUDS device must be environmental friendly and shall be tested for potential pollutant leaching from the different layers. This requires column testing to be performed. The column test effluent will be analysed for the pollutant parameters 1 to 5 listed above [13].

In addition to the testing principles listed above, the SUDs device must demonstrate a reduction in the annual TSS load by at least $92 \%$ during the testing procedure [18]. Semi-synthetic stormwater is used in the laboratory testing procedures and this is prepared according to the 90th percentile of stormwater runoff TSS concentration values found in the current literature. The artificial stormwater is then treated by the SUDS device and the difference in TSS concentrations between the influent and effluent samples are used to determine the SUDS performance. The ability of the SUDS device to remove dissolved zinc, dissolved copper, and TPH from stormwater runoff is also tested using the same methodology [18]. The SUDS device must demonstrate reductions in these pollutants of $70 \%$, $80 \%$, and $80 \%$ respectively. De-icing salts should also not influence the heavy metal removal efficiency of the SUDS device. Therefore, a further test is performed using a de-icing salt solution with a concentration of $10 \mathrm{~g} / \mathrm{L} \mathrm{NaCl}$. This test should not dislodge any previously trapped metals from the SUDS device [18].

All of the annual pollutants load tests described above are performed using four different equivalent rainfall intensities, namely $0.9 \mathrm{~mm} / \mathrm{h}, 2.2 \mathrm{~mm} / \mathrm{h}, 9.0 \mathrm{~mm} / \mathrm{h}$, and $36 \mathrm{~mm} / \mathrm{h}$. These rainfall intensities were selected after completing a comprehensive statistical analysis of the total spectrum of typical rainfall intensities across Germany.

General Technical Approvals by the DIBt [16] are only valid for a period of five years. This means, the pollution removal performance of technical SUDS devices must be revaluated following any fundamental changes to the regulations or laws. If the technical SUDS devices are not retested within an appropriate time frame, they lose their DIBt approval.

In addition to comprehensive testing of the SUDS device in the laboratory, the DIBt approvals [16] also regulate the production processes, as well as installation and operating conditions. The DIBt also stipulates that end-users must enter into ongoing maintenance contracts for SUDS devices with certified maintenance companies. Although the DIBt states that SUDS devices must be maintained by specialist companies, at this stage, there are still no clear guidelines on what training or skills a specialist maintenance company must demonstrate. This issue is still under discussion and it is anticipated that the specific requirements for SUDS maintenance contractors will be formalised within the next two years.

Developing a national testing protocol that all states are in agreement with can be a very difficult task. Table 2 provides a list of stormwater pollution testing protocols currently being used, or being developed in a number of other countries for comparison purposes.

Table 2. International sustainable urban drainage systems (SUDS) testing protocols.

\begin{tabular}{clc}
\hline Country & \multicolumn{1}{c}{ National Testing Protocol } & $\begin{array}{c}\text { Key Pollutants } \\
\text { to be tested }\end{array}$ \\
\hline \multirow{2}{*}{ USA } & $\begin{array}{l}\text { No currently accepted national testing protocol. } \\
\text { However, feasibility of a national testing program } \\
\text { currently being investigation by Water Environment } \\
\text { Federation [19] }\end{array}$ & $\begin{array}{c}\text { No current pollutant } \\
\text { removal targets }\end{array}$ \\
\hline
\end{tabular}


Table 2. Cont.

\begin{tabular}{|c|c|c|}
\hline Country & National Testing Protocol & $\begin{array}{l}\text { Key Pollutants } \\
\text { to be tested }\end{array}$ \\
\hline UK & $\begin{array}{l}\text { No current testing protocol. However, national protocol } \\
\text { currently under development by British Water }\end{array}$ & $\begin{array}{l}\text { No current pollutant } \\
\text { removal targets }\end{array}$ \\
\hline Germany & $\begin{array}{l}\text { Deutsches Institut für Bautechnik (DIBt) } \\
\text { General Technical Approval [18] }\end{array}$ & 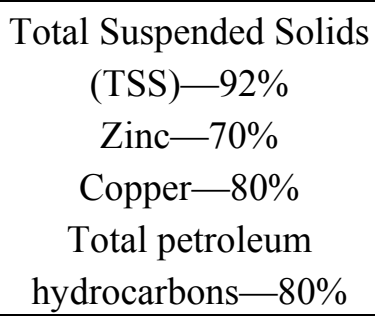 \\
\hline $\begin{array}{l}\text { The } \\
\text { Netherlands }\end{array}$ & $\begin{array}{l}\text { No official guidelines for removal efficiencies of } \\
\text { SUDS devices. However, guidelines stipulate maximum } \\
\text { acceptable pollution concentrations for SUDS } \\
\text { discharging to surface waters [20] }\end{array}$ & $\begin{array}{l}\text { Copper- }-80.5 \% \\
\text { Zinc }-60.7 \% \\
\text { Total Phosphorous } \\
\text { (TP) }-65 \%\end{array}$ \\
\hline Australia & $\begin{array}{l}\text { No current testing protocol. However, national } \\
\text { protocol currently under development by National } \\
\text { Stormwater Industry Association }\end{array}$ & $\begin{array}{c}\text { TSS }-85 \% \\
\text { TP }-45 \% \\
\text { Total Nitrogen }-45 \%\end{array}$ \\
\hline New Zealand & No current testing protocol. & $\begin{array}{l}\text { No current pollutant } \\
\text { removal targets }\end{array}$ \\
\hline Canada & No current testing protocol. & $\begin{array}{l}\text { No current pollutant } \\
\text { removal targets }\end{array}$ \\
\hline
\end{tabular}

It can be seen from Table 2 that very few countries have a fully developed SUDS device testing protocol. It can also be seen that key pollutants vary from country to country and in Germany, the focus is primarily on heavy metals from roofs and heavily polluted road runoff. This makes the German SUDS testing protocol situation quite unique in a number of contexts.

\section{Regulatory Measures to Decrease Stormwater Discharge}

Over the last few years, the councils of most German cities have introduced a new stormwater fee based on the anticipated volume of stormwater discharge from each development site. Previously in Germany, there was only one wastewater fee for each site and this included charges for both sewage and stormwater discharge. The old wastewater fee was calculated based on the potable water consumption at each site. This approach caused much discontentment among consumers as it was considered inequitable and unfair. The old fee system was seen to disadvantage owners of single family dwellings compared to owners of large industrial and commercial developments. For example, single family dwellings may have consumed (and paid for) relatively large volumes of potable water, but may have only produced minimal volumes of stormwater discharge. On the other hand, industrial and commercial developments may have only consumed minimal amounts of potable water but the sites could have generated excessive stormwater discharge volumes due to their large areas of impermeable surfaces such as roofs and car parking areas. The new stormwater fee was introduced as a result of numerous successful legal challenges to the old system. 
Owing to the large number of legal challenges to the old stormwater fee system, the German courts ruled that German councils had to introduce two wastewater fees in future: one for sewage water, and a separate one for stormwater. The sewage fee is still related to the potable water consumption. However, the new stormwater fee is calculated according to the sealed area of the development site. The fee amount differs across Germany according to local conditions. It currently ranges from $€ 0.35$ to $€ 1.92$ per square metre of sealed area producing stormwater discharge from the development site. Due to the introduction of the new stormwater fee, many land owners have since disconnected their stormwater pipes from the public sewerage systems and installed on-site stormwater infiltration facilities. If a site discharges no stormwater at all to the public sewerage system, this means no stormwater fee is payable for that site. The introduction of the new stormwater fee has seen an immediate decrease in the volumes of stormwater discharged to public sewerage systems in Germany. The new stormwater fee policy could therefore have many water quality and other environmental benefits. It has also provided a much needed boost to the development of innovative stormwater treatment and infiltration systems in Germany and Europe.

The idea to charge land owners stormwater management fees to help pay for stormwater management costs, is not new and a number of countries have implemented similar schemes in the past. For example, the New South Wales (NSW) State government in Australia amended the Local Government Act in October 2005 to allow NSW councils the option of levying a stormwater management service charge [21]. The purpose of the charge is to allow councils the option to raise additional revenue to cover some or all of the costs of providing new/additional stormwater management services within a catchment, suburb, town or local government area. While the fee is intended to reflect the percentage impervious area of a development, in order to simplify calculations and minimise administrative load, a constant impervious area is assumed for single residential dwellings, as well as for commercial and industrial land. The maximum fee for an urban residential development is $\$ 25 /$ year. Urban commercial and industrial land is charged at a rate of $\$ 25$ per $350 \mathrm{~m}^{2}$, or part thereof [21].

Many water utilities in the US apply some type of stormwater management fee to help alleviate the expense of construction, operation and maintenance of municipal stormwater treatment systems. Most of the water utilities charging fees for stormwater management in the US use a system known as the Equivalent Service Unit method where charges are proportional to the impervious area on a lot [22]. The fees generally range from $\$ 0.08$ per $1000 \mathrm{ft}^{2}\left(\sim 93 \mathrm{~m}^{2}\right)$ for undeveloped land $(0 \%$ impervious) up to $\$ 0.32$ for heavily developed land (up to $100 \%$ impervious).

The introduction of stormwater fees in Germany has produced a number of tangible benefits and has resulted in a paradigm shift in the way stormwater runoff is viewed. Reducing site stormwater runoff volumes has changed from being a "nice idea" and has become a realistic and important development design objective. Besides the more obvious benefits of reduced stormwater volumes, pollution loads and development costs, the introduction of stormwater fees has resulted in increased innovation in the treatment and management of urban stormwater. Although the effects of introducing stormwater fees in other countries is not known at this stage, the consequences and benefits of their introduction are presumably comparable to the effects in Germany. It will be interesting to see how this approach develops over the next years. 


\section{Functionality of Some Common Technical SUDS Devices}

This section provides a simple overview of the functionality and pollutant removal processes of three of the most common technical SUDS to treat stormwater runoff from urban areas (but not from metal roofs). The three SUDS are permeable pavements, filter channels and filter shaft systems.

\subsection{Permeable Pavements}

Permeable pavement construction methods are similar to those of traditional concrete block pavements. However, in contrast to traditional pavements, permeable pavements are specifically designed to allow stormwater to infiltrate through the pavement surface and into the various pavement layers and the soil below (Figure 5). This can significantly increase groundwater infiltration rates while reducing downstream runoff volumes and associated flood risk [23].

There are generally two different types of permeable pavements used in Germany: Porous Pavements, where the paving blocks are fabricated from porous concrete containing open pores to allow water to pass through it; and Permeable Interlocking Concrete Pavements (PICP), where the paving blocks are fabricated using normal concrete and the stormwater is allowed to infiltrate through the joints between the pavers and into the structure below (Figure 5). Permeable pavements can also increase evaporation rates thereby helping to restore the natural hydrological cycle. While permeable pavements can produce significant environmental benefits, their design and planning requires advanced technical knowledge and should only be undertaken by experienced designers. The highest water quality security can be achieved by using only officially approved systems [24]. Figure 5 shows a typical permeable pavement structure and porous and permeable pavers.

Most of the treatment occurs through physical (or mechanical) processes. Mullaney and Lucke [23] have shown that permeable pavements can effectively remove a variety of pollutants from stormwater including TSS, TP, TN, heavy metals and motor oils. These pollutants become trapped within the void spaces of the different pavement materials during stormwater infiltration. Heavy metals are known to adhere to the fine sediment particles [25,26], and naturally occurring chemical processes and micro-organisms break down hydrocarbons and nutrients [27,28].

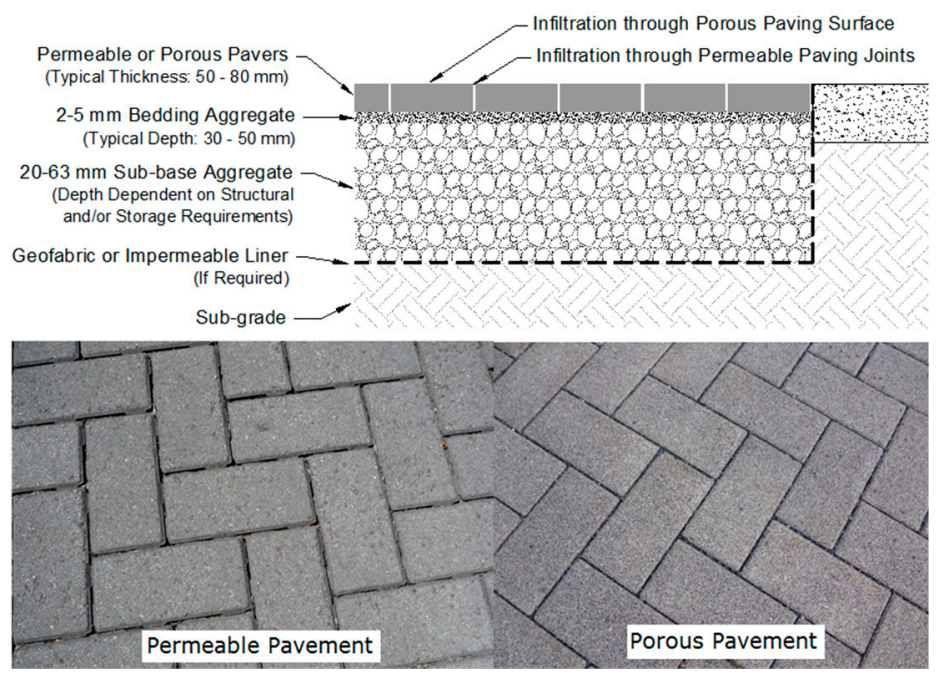

Figure 5. Typical permeable pavement structure (Top) and two different paver types (Bottom). 
Maintenance

To ensure that the infiltration performance of permeable pavements remains within the design guidelines, they generally need to be cleaned periodically. The inter-maintenance period depends on a number of factors including pavement type, location, environmental conditions and traffic volumes. They typically require cleaning at least once every 10 years [29]. For PICPs, the uppermost part of the joint needs to be rinsed or vacuumed. The joint then has to be refilled with a suitable material. The use of a combined rinsing/suction method is recommended and there are several different commercial systems available on the market.

The cleaning requirements for permeable pavements subject to DIBt approval [17] can be summarized as:

- The average infiltration capacity of the permeable pavement surfaces may not be less than $97.4 \mathrm{~mm} / \mathrm{h}\left(270 \mathrm{Ls}^{-1} \mathrm{ha}^{-1}\right)$;

- The average infiltration capacity of pavement must be measured at least once every five years [29] to ensure the surface infiltration rate is greater than or equal to $97.4 \mathrm{~mm} / \mathrm{h}$. If these measurements are not undertaken, the DIBt approvals are no longer valid and local government stormwater discharge fees may be applicable;

- If surface infiltration measurements demonstrate that the average infiltration rate is below the required $97.4 \mathrm{~mm} / \mathrm{h}$, the pavement surface shall be cleaned or reinstated to ensure compliance;

- Cleaning can be performed using trucks fitted with specialised high pressure cleaning and vacuuming systems;

- The sludge produced from pavement cleaning must be disposed of according to German Water and Waste regulations [18]; and

- After the cleaning process has been completed, the paving joints shall be refilled with the original joint filling material. Failure to refill the joints can result in serious pavement damage by vehicles.

\subsection{Filter Channels}

Engineered filter channels (or drains) consist of a linear substrate layer which collects and treats stormwater runoff through a combination of sedimentation and filtration processes. The filter media contained in the substrates function similarly to the surface soil zone in Green SUDS devices. After a rainfall event the substrate dries out. Invertebrate present within the soil media and trapped sediment produce intense activity which causes high level of bio-turbation to occur that prevents clogging [30]. Bio-turbation occurs as a result of the feeding and digestion processes [31] of terrestrial invertebrate (including bugs, worms and insects) which mix and turnover the soil and filter material and increase its porosity and infiltration capacity. Preferential flow paths are generated through the uppermost clayey sediment layer through this process. There are numerous high quality filter systems available commercially that treat stormwater runoff satisfactorily. Figure 6 shows one such typical SUDS filter channel device. 

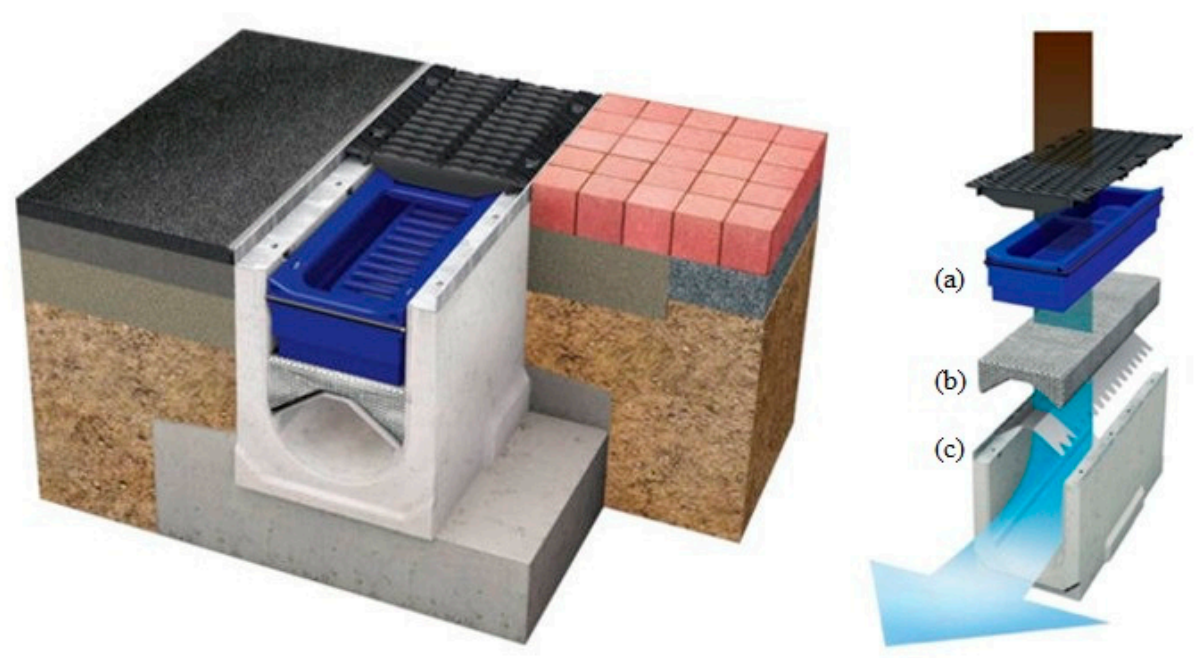

Figure 6. Typical filter channel structure: (a) sedimentation box; (b) filter bed; (c) stainless steel filter bed support [32].

A secondary filtering mechanism that occurs as a result of sediment build-up on the filter layer from the surrounding pavement areas has been observed to increase the treatment performance of filter channel systems. This secondary filter consists of particles from tyres and road surfaces that are washed off the road and deposited on the filter, and these act as a contaminant sink. The thickness of this sediment layer grows during the operation of the treatment facility and this consequently increases the sorption capacity of the SUDS filter device.

\section{Maintenance}

Engineered filter channels have been shown to effectively remove pollutants from stormwater runoff [33]. However, according to the DIBt approval requirements [17] the permeability of the substrate must be measured at least every five years [29]. In addition, measurements of the pollutant concentrations can help to prevent a breakdown of certain substances like heavy metals as there is generally a maximum sorption capacity of the filter materials for specific heavy metals. This enables the designer to take into account the influent concentration and determine a design life of the system and appropriate maintenance control. By taking samples of the filter material at different depths the effective treatment life for treating heavy metals can be predicted. This is also regulated by specific General Technical Approvals [17].

With proper inspection and maintenance, filter channels have been shown to provide effective long-term pollution reduction for stormwater runoff [33]. The following annual inspection and maintenance must be performed in order to adhere to the technical approvals specified by the DIBt [17].

- The height of the sediment on top of the filter substrate must be checked annually. If there is too much sediment on the filter, the system may no longer function correctly and must be cleaned. The maximum height of the sediment depends on the geometry of the systems and must be defined for each system individually by a suitably qualified designer;

- Assorted debris (e.g., leaves and litter) must be removed before the start of each winter period;

- The hydraulic conductivity of the filter substrate must be measured at least once every five years; 
- High waters levels in the channel may indicate clogging of the filter substrate. In this case, the filter substrate may need to be replaced; and

- The filter substrate must be replaced according to the manufacturer's requirements.

\subsection{Shaft Filter Systems}

Shaft filter systems (or proprietary pit systems) usually contain some type of sedimentation unit followed by a stormwater filter which is either integrated into, or downstream of the system. The filters function using a variety of methods including filtration, chemical precipitation, ion exchange, and adsorption. The filters can be activated vertically in both up-flow and down-flow conditions, or in a horizontal direction. Some filters are permanently submerged while others run dry after a rainfall event. There are numerous high quality commercial shaft filter systems that treat stormwater runoff satisfactorily. Figure 7 shows a typical SUDS shaft filter device.

Maintenance

All filter systems have different individual maintenance requirements. However, all systems commonly require the regular emptying of their sludge traps. In addition, the filter units must be replaced or flushed at specified intervals, generally between three months and one year. This can be done by replacing the filter units or by the replacement of the substrate. It is very important that the sludge and filter materials are disposed of correctly [33]. The maintenance requirements to abide by the general technical approvals specified by the DIBt [18] can be summarised as follows:

- Sludge levels must be periodically checked and emptied;

- All filter systems should be evaluated at least once a year;

- Ponding on the drained surface often indicates a clogged filter unit. In this case the filters must be exchanged or back flushed until they reach an acceptable hydraulic conductivity; and

- Filters or filter materials must be exchanged according to the manufacturer's instructions.

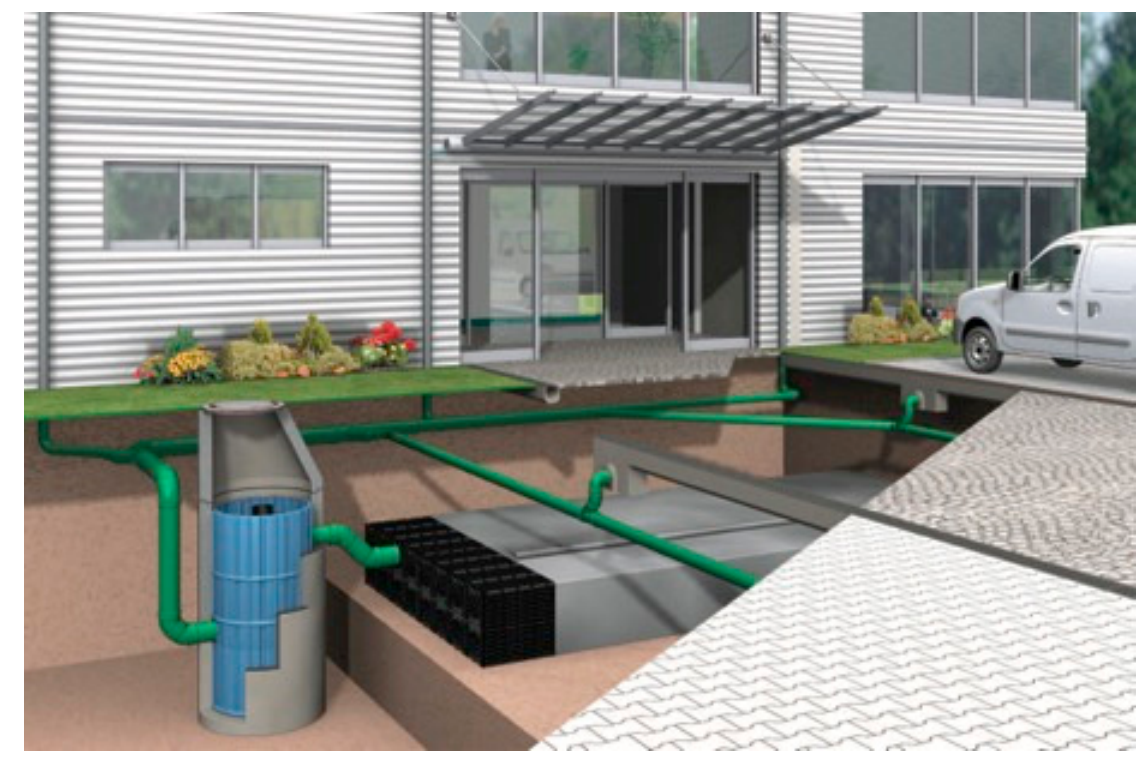

Figure 7. Typical filter shaft with underground storage and infiltration facility [34]. 


\subsection{Maintenance Security}

A maintenance contract with a suitably qualified firm is recommended for all decentralised SUDS facilities. For DIBt approved facilities such maintenance contracts are mandatory [18]. However, municipal systems may be maintained and cleaned by appropriately trained LGA personnel. The inspection and maintenance intervals of the current types of filter systems range between three months and one year. Permeable pavements and channel systems should be checked at least every five years.

For all installations, the manufacturer's instructions and recommendations should be clarified in advance. In particular, the disposal procedures for any sludge or contaminants removed from the system must be clearly outlined and agreed on by all stakeholders prior to operation. In no case is runoff or rinse water produced during maintenance procedures allowed to enter a storm sewer or infiltration system. Even when changing filters or substrates, the material must be properly treated or disposed of. Most manufacturers now offer to accept the return of the contaminated filters.

\section{Summary}

Decentralised SUDS offer a good alternative to end of pipe treatment systems for stormwater runoff from urban areas. However, their use is highly dependent on the individual catchment situation. Each catchment should therefore be carefully investigated to determine whether centralised or decentralised systems would be the most appropriate and feasible option to provide protection for the different types of downstream receiving waters. For example, small creeks and lakes can have very different treatment and environmental requirements to large rivers or coastal watercourses and this may significantly influence the choice between centralised or decentralised systems.

Decentralised SUDS should generally be recommended where space is limited and centralised solutions are more difficult to implement. For relatively clean stormwater runoff from non-metal roofs and areas with no or low traffic densities, green SUDS such as swales or rain gardens should generally be implemented. These SUDS detain stormwater runoff and allow it to infiltrate slowly through the top soil and into the water table. Decentralised green SUDS treatment devices generally have an average footprint of approximately $20 \%$ of the drained area which is usually lower than the requirement for centralised systems.

In catchments containing a variety surfaces with mostly clean runoff and only some areas with polluted runoff, a combination of green and technical SUDS can be used to reduce the costs for stormwater treatment. That means that SUDS treatment of stormwater runoff at source is often the best alternative in dense urban areas. However, lower construction costs for some SUDS systems can be negated by higher costs for maintenance and operation. Therefore, the full life cycle costs should be considered at the planning stage to enable a realistic and accurate cost comparison.

Tests and approval processes provide important information about the operation and the theoretical efficiencies of decentralised SUDS devices. The DIBT General Technical Approvals [18] therefore provide security in the decision making process. However, in order to correctly assess whether decentralised SUDS systems will provide the level of water resource protection required, a number of other aspects should ideally also be considered. These include: 
- Results of detailed laboratory tests by independent institutes, such as fulfilling the criteria of DIBt [28], or other specific state regulations;

- Additional laboratory testing is recommended to provide performance diagnostics over the entire expected operational range of hydraulic conditions;

- Results of in-situ measurements over sufficiently long time periods should also be provided, and if possible, at a number of different locations. This is not part of the approval process but is highly recommended in order to provide valuable addition operational information. These reports should include good descriptions of the measurement boundary conditions (i.e., location, type of connected surface, rainfall characteristics, location and type of sampling, number of samples, number of rainfall events, load calculations); and

- General notes and instructions for operation (i.e., detailed maintenance instructions, cost estimates for operation and maintenance, and if possible, outlines for maintenance contracts).

The maintenance of decentralised SUDS devices should be regulated in advance and taken into account in the initial project costing calculations. In addition, maintenance of SUDS devices should only be performed by suitably qualified personnel. Most approvals of DIBt [18] require the completion of maintenance contracts. Since decentralised catchment areas show a higher variability of pollutants in stormwater runoff, SUDS device installations should be checked more often, particularly during the first two years of operation. Where appropriate, maintenance intervals should be adapted to site specific conditions. Compliance with the above-mentioned requirements should ensure reliable, successful and long-lasting operation of decentralised SUDS devices.

While discharge to receiving waters can be considered a highly dynamic process where short-term peak pollution loads can be important, it must also be recognised that runoff infiltration processes can result in long-term accumulation of pollutants in the soil and underlying water table. Soil and groundwater pollution could potentially have a much greater long-term environmental effect than receiving water pollution. This could further complicate future stormwater management strategies and will need to be considered in more detail in future.

\section{Conclusions}

This paper provides a practical outline of the current urban stormwater treatment requirements, and of the general technical approval processes for decentralised SUDS devices in Germany. The paper discussed:

- Decentralised SUDS can offer a viable and attractive alternative to end of pipe treatment systems for stormwater runoff from urban areas.

- Allowable pollution levels in stormwater runoff that infiltrate into ground and/or water table are regulated by the Federal Soil Protection Law which is valid across Germany.

- At present, there is no federal law addressing the discharge requirements for surface water runoff. However, new guidelines are currently being developed by the DIBt.

- North Rhine Westphalia has adopted its own stormwater treatment guidelines which stipulate different levels of treatment for stormwater runoff from different land uses. 
- New federal regulations in Germany stipulate that heavily polluted stormwater runoff must be treated separately at source.

- New DWA A102 guidelines generally require decentralised SUDS devices to remove at least $50 \%$ of particles less than $63 \mu \mathrm{m}$ in size from stormwater runoff.

- Many German cities have introduced a new stormwater fee based on the anticipated volume of stormwater discharge from each development site.

- General technical approvals for SUDS devices currently being developed by the DIBt will only be valid for a period of five years after which time the devices must be re-tested.

- Maintenance is required for all SUDS devices by suitably qualifies personnel to ensure long-term, reliable performance. Maintenance contracts are mandatory for DIBt approved SUDS devices.

This study discussed and clarified the new technical approval guidelines for decentralised SUDS devices in Germany. This knowledge should aid researchers, designers and asset managers to better test the performance, effective life-spans, and develop better planning and maintenance requirements for decentralised SUDS systems. This could potentially promote even greater use of innovative technical stormwater treatment systems in the future.

\section{Author Contributions}

This study was undertaken as a collaborative research project between the Urban Water Management Centre at the Frankfurt University of Applied Sciences in Germany, the Stormwater Research Group at the University of the Sunshine Coast in Australia and the Urban Water Systems Engineering Centre at the Technical University of Munich, in Germany. The paper was written by all three authors equally.

\section{Conflicts of Interest}

The authors declare no conflicts of interest.

\section{References}

1. Green Roof Example. Available online: http://en.wikipedia.org/wiki/Green_roof\#mediaviewer/ File:20080708_Chicago_City_Hall_Green_Roof.JPG (accessed on 8 July 2008).

2. Sedimentation Tank Example. Available online: http://spel.com.au/products/triceptor/ spel-triceptor-gallery/ (accessed on 9 March 2015).

3. Silt Basket Example. Available online: http://spel.com.au/products/spel-stormsack/ spel-stormsack-gallery/ (accessed on 9 March 2015).

4. Filter Gully Example. Available online: http://www.3ptechnik.com.au/25-3-HydrofilterGulley.html (accessed on 9 March 2015).

5. Eriksson, E.; Baun, A.; Scholes, L.; Ledin, A.; Ahlman, S.; Revitt, M.; Noutsopoulos, C.; Mikkelsen, P.S. Selected stormwater priority pollutants: A European perspective. Sci. Total Environ. 2007, 383, 41-51.

6. Werkenthin, M.; Kluge, B.; Wessolek, G. Metals in European roadside soils and soil solutions-A review. Environ. Pollut. 2014, 189, 98-110. 
7. Dierkes, C.; Welker, A.; Dierschke, M. Development of testing procedures for certification of decentralised storm water treatment facilities-Results from laboratory investigations. In proceedings of 8th International Novatech Conference, Lyon, France, 23-27 June 2013.

8. Schriewer, A.; Horn, H.; Helmreich, B. Time focused measurements of roof runoff quality. Corros. Sci. 2008, 50, 384-391.

9. Athanasiadis, K.; Horn, H.; Helmreich, B. A field study on the first flush effect of copper roof runoffs. Corros. Sci. 2009, 52, 21-29.

10. Helmreich, B.; Hilliges, R.; Schriewer, A.; Horn, H. Runoff pollutants of a highly trafficked urban road - Correlation analysis and seasonal influences. Chemosphere 2010, 80, 991-997.

11. Gesetz zur Ordnung des Wasserhaushalts (Wasserhaushaltsgesetz WHG). Available online: http://www.gesetze-im-internet.de/bundesrecht/whg_2009/gesamt.pdf (accessed on 24 February 2015). (In German)

12. Runderlass: Anforderungen an die Niederschlagsentwässerung im Trennverfahren. Available online: http://www.lanuv.nrw.de/wasser/abwasser/nw.htm (accessed on 24 February 2015). (In German)

13. Bundes Bodenschutz und Altlastenverordnung. Available online: http:/www.gesetze-iminternet.de/bundesrecht/bbodschv/gesamt.pdf (accessed on 4 January 2015). (In German)

14. Dezentrale Niederschlagswasserbehandlung in Trennsystemen-Umsetzung des Trennerlasses. Available online: http://www.lanuv.nrw.de/wasser/abwasser/forschung/pdf/20111125_ Gesamtbericht.pdf (accessed on 14 February 2014). (In German)

15. Schmitt, T.G. Weiterentwicklung des DWA-Regelwerks für Regenwetterabflüsse-ein Werkstattbericht. KA-Abwasser, Abfall 2012, 59, 192-199. (In German)

16. Prüfverfahren DIBt: Darstellung der Historie und Grundlagen. Available online: https://www.dibt.de/en/Departments/Data/Ref_II_3_Vortrag_Pr\%C3\%BCfverfahren_DIBt.pdf (accessed on 24 February 2015). (In German)

17. Maßnahmen zur Niederschlagswasserbehandlung in kommunalen Trennsystemen am Beispiel des Regierungsbezirks Köln. Available online: http://www.lanuv.nrw.de/wasser/abwasser/forschung/ pdf/Abschlussbericht.pdf (accessed on 14 February 2015). (In German)

18. Entwicklung einer Prüfvorschrift für dezentrale Behandlungsanlagen für Verkehrsflächenabflüsse bei Einleitung in Oberflächengewässer. Available online: http:/www.lanuv.nrw.de/wasser/abwasser/ forschung/pdf/Bericht_Welker_01_2014.pdf (accessed on 24 February 2015). (In German)

19. Netherlands Ministry of Transport, Public Works and Water Management. NW4-Fourth National Policy Document on Water Management; Netherlands Ministry of Transport, Public Works and Water Management: The Hague, The Netherlands, 1998.

20. Investigation into the Feasibility of a National Testing and Evaluation Program for Stormwater Products and Practices. Available online: http://www.wef.org/uploadedFiles/Access_Water_ Knowledge/Stormwater_and_Wet_Weather/Stormwater_PDFs/WEF-STEPP-White\%20Paper_ Final_02-06-14(2).pdf (accessed on 10 March 2015).

21. Stormwater Management Service Charge Guidelines. Available online: http://www.dlg.nsw.gov.au/ $\mathrm{dlg} / \mathrm{dlghome} /$ documents/Information/06-47\%20-\%20Stormwater\%20Guidelines.pdf (accessed on 24 February 2015).

22. Funding Stormwater Programs. Available online: http://water.epa.gov/infrastructure/ greeninfrastructure/upload/FundingStormwater.pdf (accessed on 10 March 2015). 
23. Mullaney, J.; Lucke, T. Practical review of pervious pavement designs. CLEAN Soil Air Water 2014, 42, 111-124.

24. Welker, A. Bauaufsichtliche Zulassungen von dezentralen Niederschlagswasserbehandlungsanlagen. In Proceedings of der Wasser Berlin International 2013, Fachmesse und Kongress Wasser und Abwasser, Berlin, Germany, 22-26 April 2013.

25. Goonetillekea, A.; Thomas, E.; Ginn, S.; Gilbert, D. Understanding the role of land use in urban stormwater quality management. J. Environ. Manag. 2005, 74, 31-42.

26. Sartor, J.D.; Boyd, G.B. Water Pollution Aspects of Street Surface Contaminants; Report No. EPA-R2-72/081; US Environmental Protection Agency: Washington, DC, USA, 1972.

27. Scholz, M.; Lee, B. Constructed wetlands: A review. Int. J. Environ. Stud. 2005, 62, 421-447.

28. Nogaro, G.; Mermillod-Blondin, F.; Montuelle, B.; Boisson, J.C.; Bedell, J.P.; Ohannessian, A.; Volat, B.; Gibert, J. Influence of a stormwater sediment deposit on microbial and biogeochemical processes in infiltration porous media. Sci. Total Environ. 2007, 377, 334-348.

29. Prüfung wasserdurchlässiger Flächenbeläge nach mehrjähriger Nutzungsdauer. Available online: http://www.ikt.de/website/down/f0146langbericht.pdf (accessed on 10 March 2015). (In German)

30. Kazemi, F.; Beecham, S.; Gibbs, J. Streetscape biodiversity and the role of bioretention swales in an Australian urban environment. Landsc. Urban Plan. 2011, 101, 139-148.

31. Anderson, J.M. Spatiotemporal effects of invertebrates on soil processes. Biol. Fertil. Soils 1988, 6, 216-227.

32. Filter Channel Example. Available online: http://www.birco.de/BIRCOpur.6739.0.html (accessed on 10 March 2015).

33. Welker, A.; Huber, M. Dezentrale Behandlungsanlagen für Verkehrsflächenabflüsse-Stand der Technik. Zukunftsfähige Bewirtschaftungskonzepte für Niederschlagswasser 2014, 211, 89-106. (In German)

34. Filter Shaft Example. Available online: http://www.rehau.com/de-de/bau/abwasser-wasserwirtschaft/ rehau-auf-dem-rohrleitungsforum-oldenburg-2012/773256 (accessed on 10 March 2015).

(C) 2015 by the authors; licensee MDPI, Basel, Switzerland. This article is an open access article distributed under the terms and conditions of the Creative Commons Attribution license (http://creativecommons.org/licenses/by/4.0/). 